\title{
DEVELOPMENT OF AN ADVANCED COMPOSITE SYSTEM FORM FOR CONSTRUCTABILITY IMPROVEMENT THROUGH A DESIGN FOR SIX SIGMA PROCESS
}

\author{
Dongmin LEE ${ }^{1} 1$, Taehoon $\mathrm{KIM}^{1 *}$, Dongyoun $\mathrm{LEE}^{1}$, \\ Hyunsu LIM ${ }^{2}$, Hunhee $\mathrm{CHO}^{1}$, Kyung-In KANG ${ }^{1}$ \\ ${ }^{1}$ School of Civil, Environmental and Architectural Engineering, Korea University, Seoul, South Korea \\ ${ }^{2}$ Department of Architecture, Soonchunhyang University, Asan-si, South Korea
}

Received 06 September 2019; accepted 28 October 2019

\begin{abstract}
System form is widely used when constructing concrete buildings and structures because it has high productivity and good concrete casting quality compared with traditional hand-set form. However, from a worker's perspective, system form is still very harsh to handle because of its heavy weight, noise generation, and use of releasing agent, and it also attenuates the productivity of system formwork. Therefore, this study proposes the use of an advanced composite material-based concrete form for workers using a Design for Six Sigma (DFSS) process to improve constructability of system formwork. User requirements are systematically reflected in the technical characteristics of concrete form, and innovative principles are scientifically organized through the DFSS process that mainly consists of quality function deployment and theory of creative problem-solving methods. The proposed composite form showed improved performance in deriving high-quality formwork and worker-friendly working conditions compared with previous system forms. Additionally, this study demonstrated how the DFSS will be a valuable tool for technology development and systematic decision-making in building construction.
\end{abstract}

Keywords: composite form, system concrete form, formwork, Design for Six Sigma (DFSS), quality function deployment (QFD), theory of creative problem-solving (TRIZ).

\section{Introduction}

System formwork is a systematic support method for forming cast-in-place concrete structures in building construction until the concrete can support itself (Lee, 2019). It uses standard prefabricated modular units with various sizes of formwork panels. The modular components are assembled on-site in different combinations with the aid of computer-aided design (Lee et al., 2018), and minor conventional formwork typically made of timber is required to complement the system by filling gaps. The system form has high productivity and good casting quality as well as can be recycled more times than conventional forms such as timber and wood-based form, and various types of system form have been developed to suit the required shapes of concrete structures with less effort, especially in urban city construction.

Some of the most widely used system forms in midand high-rise buildings are steel (Euro form) and aluminum forms (Al-form) (Kim, 2013). They have high repeat uses and are simple, cost-efficient, productive, and easy to handle (Liang, 2010). However, despite their advantages, they are still heavy to carry and cumbersome to lift by hand (Chang-Yeob et al., 2010), which reduce formwork productivity. In addition, they contribute to noise generation in building construction sites in urban areas, leading to many complaints from residents around the site and making the working environment very harsh. In addition, high investment cost (Vivek, 2016) and the environmental problems caused by the heavy usage of releasing agents to ease the stripping work of concrete means that there is a need to develop a new system form (Kim et al., 2010). Several existing studies suggested formwork planning model (Lim et al., 2017) and the equipment-centric formwork method (Kim et al., 2012) to solve such problems. These studies confirmed that formwork productivity can be improved by using the suggested planning model and new formwork method. However, they could not sufficiently

*Corresponding author. E-mail: kimth0930@korea.ac.kr 
solve fundamental problems of form to satisfy the workers, such as heavy weight, noise generation, cost overrun and environment issues (Lee, 2019).

Using composite-based concrete form can be a good solution to solve the aforementioned problems. A composite is a material made from two or more constituent materials with significantly different physical or chemical properties, but the materials retain their individual characteristics (Fazeli et al., 2019). There are various functional and technical requirements when designing a new system form (Lim et al., 2012), and the composite can provide a good approach to satisfy them. For designing a new composite concrete form, it is necessary to apply scientific design process and techniques that can both qualitatively and quantitatively satisfy the user's functional and technical requirements.

Design for Six Sigma (DFSS) is a structured approach to developing new products by incorporating multiple design methodologies (Liverani et al., 2019). DFSS has the objective of determining the requirements of customers, translating the requirements into product solutions ( $\mathrm{He} \&$ Ngee Goh, 2015). There are various design tools in a DFSS, but the present study focused on two methodologies, quality function deployment (QFD) and theory of creative problem solving (TRIZ). QFD is a customer-oriented tool to translate the requirements of the customer (user) into technical attributes of a product (Prasad, 1998; Temponi et al., 1999). Furthermore, QFD can quantify and present the priorities of improvements while converting user requirements into technical (engineering) characteristics. In addition, TRIZ is used to propose innovative solutions with numerous tools that enable a targeted and systematic problem-solving method (Tursch et al., 2015).

Previously, Wang et al. (2016) applied DFSS and TRIZ for new network devices. Liverani et al. (2019) suggested an interactive engineering design and development process using DFSS and QFD and conducted a case study of a multifunctional fan. Their results show that the DFSS can be an effective process for developing a new product. By contrast, Mayda and Borklu (2014) implemented TRIZ to identify innovative concepts during engineering design and then used QFD to meet customers' needs. Yeh et al. (2011) conducted a notebook computer case study by using the integration of QFD and TRIZ. Lim et al. (2012) designed an innovative table form for high-rise building construction using QFD and TRIZ. They verified that integrating QFD and TRIZ resulted in good synergy in product design.

The purpose of the present study was to develop a new system form to solve previous formwork issue such as heavy weight, noise generation, cost overrun and environment issue enough for satisfying the workers using composite material. By applying DFSS and integrating QFD and TRIZ, we designed a new form incorporating the user's requirements because the constructability of the construction starts with the ease of the worker. The newly developed form is compared with Al-form and Euro form (steel), which is the most widely used form in mid- and high-rise building construction in the world.

\section{Research methodology}

\subsection{Design for Six Sigma (DFSS)}

DFSS is a proactive design approach to develop a new product or process as it incorporates multiple methodologies (Liverani et al., 2019). DFSS aims to incorporate customers' needs into the product solution and to verify that new products meet the standards of environment for which they are designed (De Feo \& Bar-El, 2002; ElSharkawy et al., 2014; Hasenkamp, 2010). DFSS comprises the following five phases: Define, Measure, Analyze, Design, and Validate. Each of these phases requires tools to ensure that the product and process design are conducted seamlessly and appropriately, and the DFSS approach is described through the following scheme (Figure 1).

\subsection{Importance performance analysis (IPA)}

IPA is a method that simultaneously compares the relative importance and performance of each property to measure the priorities among attributes. IPA has been widely used to prioritize customer needs in the business and engineering fields in recent years (Lee et al., 2017). Prioritization is a process of deciding what should be considered first based on what will bring the most value to the customer and what is feasible. To use IPA, a questionnaire asking about the importance and performance of each attribute was distributed to users who are surveyed on a five- or seven-point Likert scale. The average value of each attribute is calculated and marked on a four-quadrant grid, with the vertical axis representing the importance and the horizontal axis representing the performance. The graphic representation provides an understandable guide for identifying the crucial product or service attributes in terms of customer's needs for managerial action (Geng \& Chu, 2012).

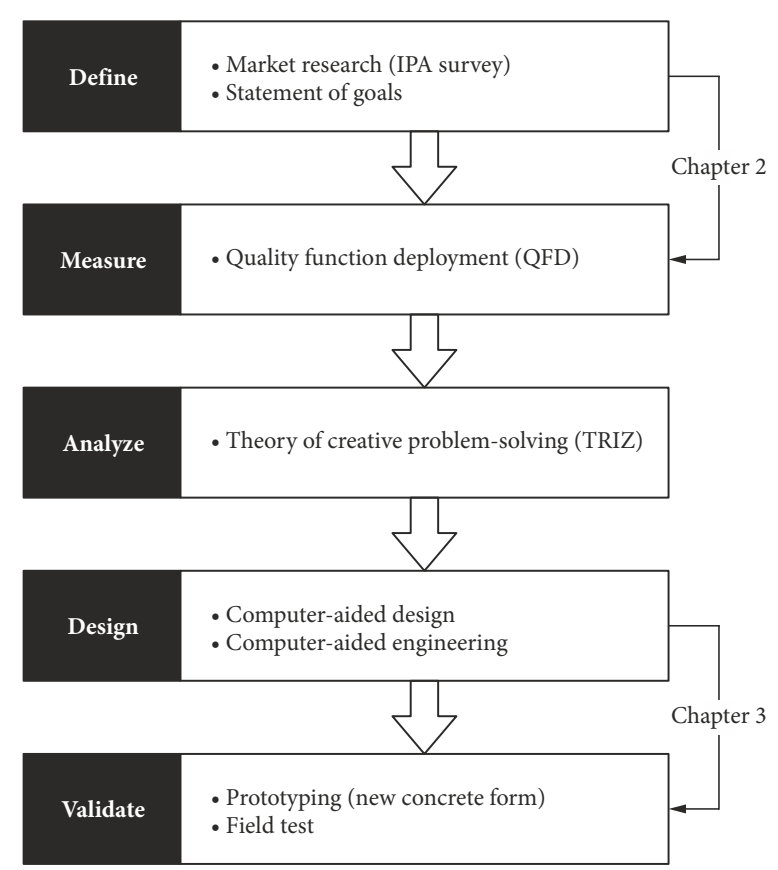

Figure 1. DFSS process 
If an attribute is located in quadrant 4 , then the attribute is very important, but the current status does not satisfy the users; consequently, the attribute needs to be improved with higher priority. This study used an importance index (importance score divided by performance score) for quantitative analysis and to find higher priority among attributes.

\subsection{QFD structure and TRIZ overview}

\subsubsection{QFD}

QFD has been used successfully to assist product developers in systematically incorporating customer requirement (CR) into engineering characteristic (EC) to plan and manage product and process development (Akao et al., 1990). From the interrelationships between CRs and ECs and the correlations between ECs, the main task of product planning using QFD is to determine target values of ECs to achieve higher overall customer satisfaction (Fung et al., 2005). The House of Quality (HOQ) is a customer analysis tool and a key component of the QFD technique that aids in determining how well a product meets customer needs. Although quite intricate, HOQ can store a large amount of information and compare large amounts of data used for defining the relationship between customer desires and ECs. The HOQ consists of six procedures, as shown in Figure 2. The relationships (3), how they affect each other, between CRs (1) and ECs (2) are evaluated by survey. And considering the relationships and priority of CRs, technical importance of ECs are calculated on the technical matrix (4)). To avoid scarifying other ECs during improving a EC, correlations (5) between ECs are evaluated. Solutions for improving the customer satisfactions will be provided on the planning matrix (6)).

\subsubsection{TRIZ}

TRIZ was proposed by the Russian researcher Altshuller (2002), who used it to solve creative problems that usually have the features of paradoxical and conflicting demands (Hua et al., 2006). TRIZ is a unique method of systemati-

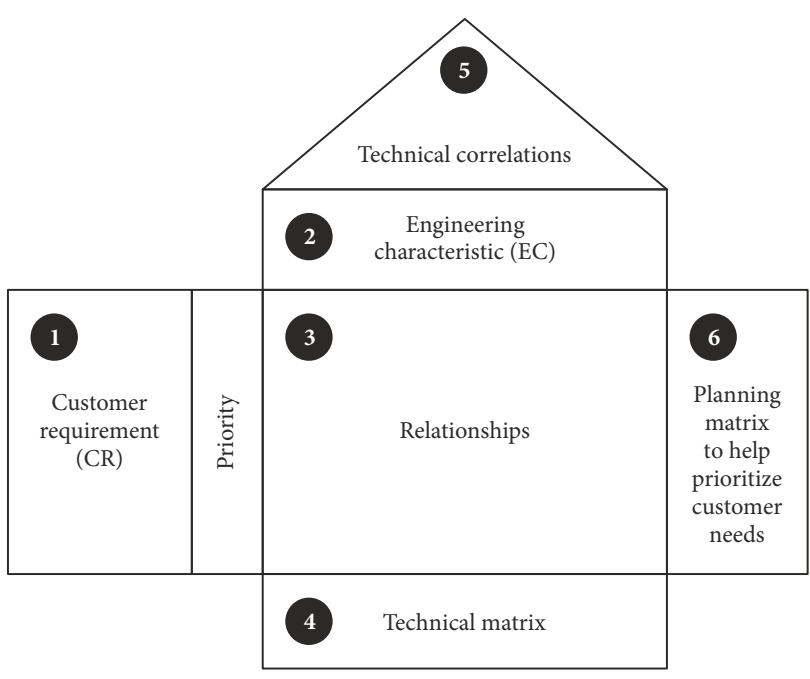

Figure 2. The HOQ cally thinking with a useful knowledge base as its foundation. Therefore, it is helpful for generating breakthrough ideas and delivering solutions (Sheu \& Hou, 2013). TRIZ has been used to analyze and summarize problems with a $39 \times 39$ contradiction matrix using the 39 engineering features shown in Table 1; it also includes the 40 innovative principles corresponding to the contradiction matrix shown in Table 2 (Wang et al., 2017). TRIZ has been widely studied in previous studies, which confirm that TRIZ can improve designs and innovations for product development (Fey \& Rivin, 2005; Vinodh et al., 2014; Yamashina et al., 2002).

Table 1. Thirty-nine TRIZ engineering features

\begin{tabular}{|c|c|}
\hline $\begin{array}{l}\text { 1. Weight of moving object } \\
\text { 2. Weight of stationary object } \\
\text { 3. Length of moving object } \\
\text { 4. Length of stationary object } \\
\text { 5. Area of moving object } \\
\text { 6. Area of stationary object } \\
\text { 7. Volume of moving object } \\
\text { 8. Volume of stationary object } \\
\text { 9. Speed } \\
\text { 10. Force } \\
\text { 11. Stress or pressure } \\
\text { 12. Shape } \\
\text { 13. Stability of the object's } \\
\text { composition } \\
\text { 14. Strength } \\
\text { 15. Duration of action by a } \\
\text { moving object } \\
\text { 16. Duration of action by a } \\
\text { stationary object } \\
\text { 17. Temperature } \\
\text { 18. Illumination intensity } \\
\text { 19. Use of energy by a moving } \\
\text { object } \\
\text { 20. Use of energy by a stationary } \\
\text { object }\end{array}$ & $\begin{array}{l}\text { 21. Power } \\
\text { 22. Loss of energy } \\
\text { 23. Loss of substance } \\
\text { 24. Loss of information } \\
\text { 25. Loss of time } \\
\text { 26. Quantity of substance/ } \\
\text { the matter } \\
\text { 27. Reliability } \\
\text { 28. Measurement accuracy } \\
\text { 29. Manufacturing } \\
\text { precision } \\
\text { 30. External harm affects } \\
\text { the object } \\
\text { 31. Object-generated } \\
\text { harmful factors } \\
\text { 32. Ease of manufacture } \\
\text { 33. Ease of operation } \\
\text { 34. Ease of repair } \\
\text { 35. Adaptability or } \\
\text { versatility } \\
\text { 36. Device complexity } \\
\text { 37. Difficulty of detecting } \\
\text { and measuring } \\
\text { 38. Extent of automation } \\
\text { 39. Productivity }\end{array}$ \\
\hline
\end{tabular}

Table 2. Forty TRIZ innovative principles

\begin{tabular}{l|l|}
$\begin{array}{l}\text { 1. Segmentation } \\
\text { 2. Separation }\end{array}$ & 21. Hurrying \\
3. Local quality & 22. Blessing in disguise \\
4. Symmetry change & 23. Feedback \\
5. Merge & 25. Intermediary \\
6. Multi-functionality & 26. Copying \\
7. Nested doll & 27. Cheap disposables \\
8. Weight compensation & 28. Mechanical interaction \\
9. Preliminary counteraction & \multicolumn{1}{|c|}{ substitution } \\
10. Preliminary action & 29. Pneumatics \& hydraulics \\
11. Beforehand compensation & 30. Flexible shells \& thin film \\
12. Equi-potentiality & 31. Porous materials \\
13. The other way around & 32. Optical property changes \\
14. Curvature increase & 33. Homogeneity \\
15. Dynamic parts & 34. Discarding \& recovering \\
16. Partial or excessive actions & 35. Parameter change \\
17. Dimensionality change & 36. Phase transition \\
18. Mechanical vibration & 37. Thermal expansion \\
19. Periodic action & 38. Strong oxidants \\
20. Continuity of useful action & 39. Inert atmosphere \\
\multicolumn{2}{|l}{}
\end{tabular}




\subsubsection{QFD + TRIZ}

QFD has a limitation in deriving reasonable solutions through reflecting correlations between TCs. In this case, a contradiction matrix - an effective TRIZ tool - can help break up a complex design problem into incentive principles and provide several alternative innovative solutions. This study correlated the analysis results of the TCs of the HOQ's roof with the contradiction matrix of TRIZ (Figure 3). Two TCs with a negative correlation between each required technology characteristic derived through the HOQ were collected and translated into 39 standard characteristics, and innovative solutions were derived by applying them to the contradiction matrix. In this manner, we were able to clearly explain the contradictions of technical features and find scientific and creative solutions through the principles of generic invention.

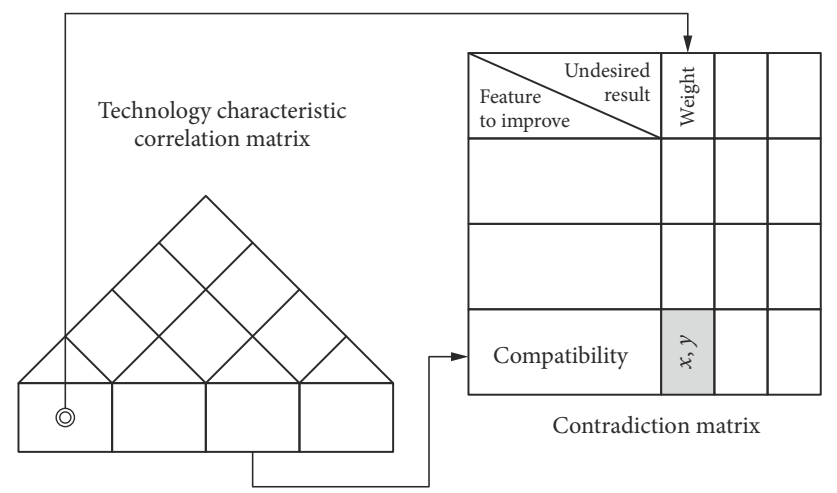

Figure 3. Principles of integrating QFD and TRIZ

\subsection{Design process for the concrete system form for building construction using the integration of QFD and TRIZ}

The design process for the new concrete system form using the HOQ of QFD and the TRIZ innovation principle are described in the nine steps shown in Figure 4.

\subsubsection{Transforming the TCs of the required quality using QFD}

Step 1: Deriving the required qualities of formwork for building construction

Through interviews and questionnaires with users, we collected the critical quality requirements of the system form. Site managers, framers, and developers of the formwork system were included as users, and the qualities required for the improvement of the form were determined through the questionnaires. The importance and performance of the properties were also collected through the questionnaires. The weights assigned to the QFD categories were calculated using the IPA method.

Step 2: Converting the deduced required qualities into the technical (engineering) characteristics of the system form

Through meetings with the expert group, technical features such as the size, structure, and shape of the system form were derived. A group of experts with at least 10 years of experience in developing formwork systems in a formwork company participated in the meetings to deduce the practicality and TCs in detail.

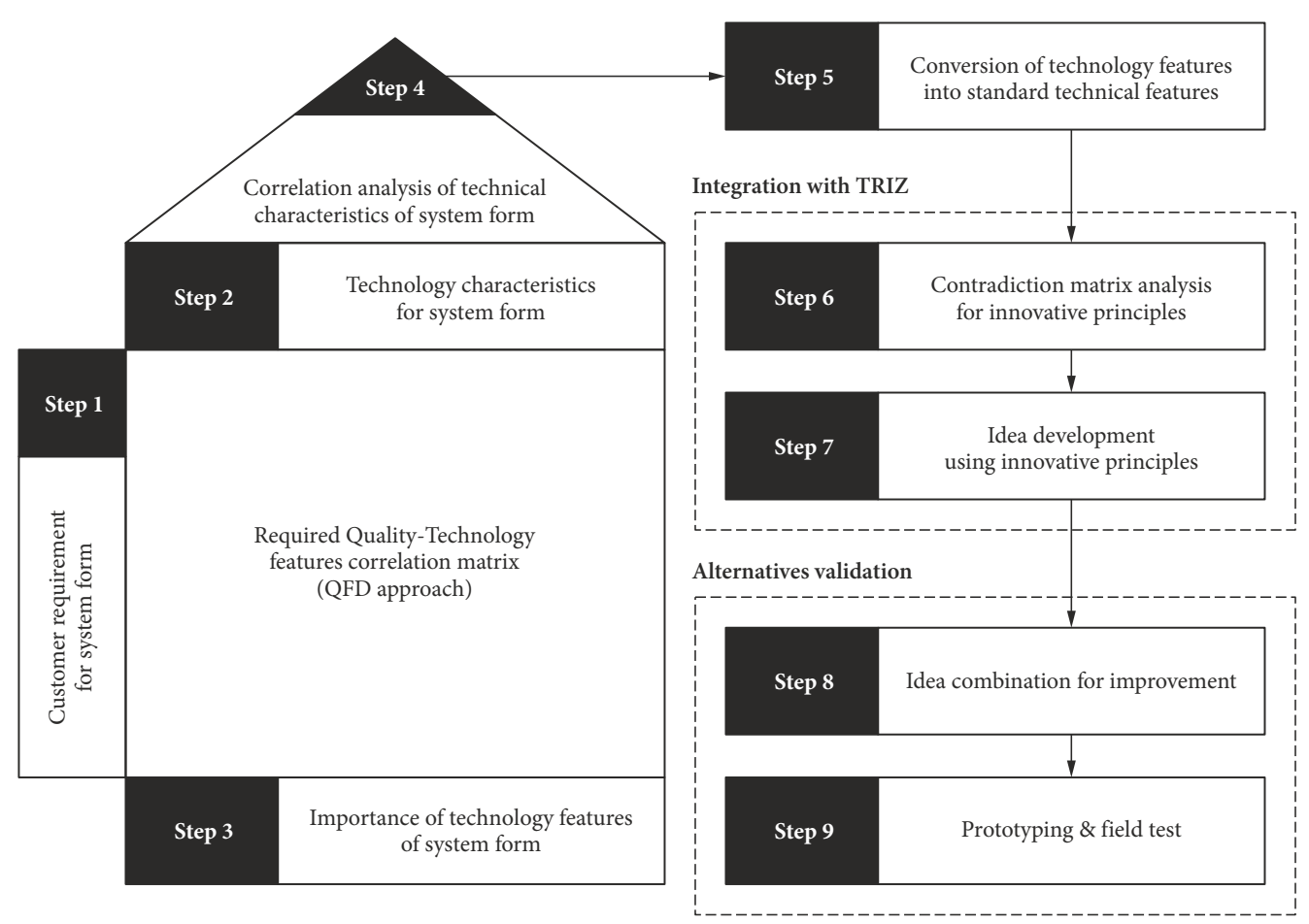

Figure 4. Design process for the concrete system form using QFD and TRIZ 
Step 3: Assessing the importance of the TCs of the system form

It is crucial to understand which TCs of the system form are more important. We derived the importance of the TCs by analyzing the correlation between the required qualities and the TCs to determine their level of priority. Because the correlation analysis stage also requires a clear understanding of the target system form, the level of correlation between each required quality and TC was evaluated on the scale of 1,3, and 9 to make larger gaps between choices by the same expert group (Cohen, 1995). The importance of each TC was quantified by multiplying the correlation degree by the importance of the corresponding requirement quality. The quantified TCs were then ranked and prioritized.

Step 4: Interpretation of TCs of the system form

We analyzed the correlations between high-priority and other TCs. A positive correlation between technological characteristics means that they go through the process of integration, while a negative correlation indicates a contradiction problem.

Step 5: Conversion of standard characteristics to system TCs

To solve the contradiction problems, we converted the TCs of formwork that were negatively correlated into standard properties in the contradiction matrix. Because the TCs derived from the HOQ and the 39 standard characteristics presented in the contradiction matrix cannot be precisely matched, it is necessary to convert them to related standard characteristics. These were applied in the next step, the contradiction matrix.

Step 6: Deriving the principle of invention through analysis of the contradiction matrix

We applied the transformed standard characteristics to the contradiction matrix. The characteristic to be improved is displayed as a row, while a characteristic that is degraded by the improvement is displayed in a column, and the principle of the invention is derived by finding the intersections.

\section{Step 7: Deriving ideas using inventive principles}

An existing general solution was derived through the principle of invention. It can serve as a guide for finding ideas for resolving contradictions through inventive principles and technology cases that solve the existing contradiction problem. Next, we derived ideas for quality improvement and contradiction resolution through recursive thinking using general solutions. We presented the directions of ideas through the invention principle and existing cases and created and organized ideas.

Step 8: Drawing out ideas for improvement through a combination of ideas

By combining the derived ideas, an improvement plan for the concrete form was derived. Through combining ideas that consider the whole system operation process, an improvement plan for the skyscraper formwork system was derived.
Step 9: Deriving final alternatives through prototyping and field testing

Based on the improvement plan of the formwork system, a prototype was produced and applied on a construction site (this process is described elsewhere).

\section{Development of new system form through a DFSS process}

\subsection{Define: Market research and goal statement}

\subsubsection{Derivation of CRs}

To derive the customer (worker) requirements of concrete system form, the first interviews were conducted with two supervisors of two high-rise building construction projects, four heads of formwork companies, and six on-site experts in system formwork. Through these interviews, we derived 17 CRs for improving the application of concrete system form. A second individual interview was conducted using the derived CRs, and an additional four requirements were derived. Some redundant CRs were combined to obtain the final 15 requirements alternatives as the required qualities, excluding the requirements with weight.

The goal of the DFSS process is to make an advanced system form satisfying workers' requirements. A concrete form consisting mainly of a single material was restructured into composite materials according to workers' requirements. The DFSS provides systematic and scientific methodology for developing a new system form considering the requirements.

\subsubsection{Deriving the priorities of CRs through IPA survey}

We conducted an IPA survey to determine the importance of CRs. To reflect the demands of actual formwork users, the questionnaire was limited to on-site construction supervisors and workers. An IPA questionnaire was conducted with 40 users to assess the qualities required for the use of concrete system form, and a total of 35 user questionnaires were acquired excluding five questionnaires that included missing or inconsistent data. IPA techniques were applied to prioritize the weights of CRs in QFD. The questionnaire was conducted using a fivepoint Likert scale. When analyzed by the internal consistency method, the Cronbach's alpha values of the questionnaires collected in this study were 0.984 for importance and 0.963 for performance. Therefore, the questionnaire data collected in this study were found to be reliable.

From the survey, the overall importance of CRs and design characteristics were deduced by categories (Table 3 ). The IPA survey also included the performance criteria to exclude the specific CRs that were already performed or managed well, and thus, did not require improvement. The importance score obtained from the IPA questionnaire divided by the performance score was converted into a score of 100, which was used as the importance index of CRs. Highest in the order of importance were: CR1: Easy assembly and disassembly; CR2: Reduced noise dur- 
ing dismantlement or assembly and disassembly; CR13: Compatible with existing formwork units; CR7: High repeat use with constant module size; CR15: Provide various module sizes to minimize on-site work; CR4: Efficient lifting and carrying; and CR12: High concrete surface quality.

\subsection{Measure: QFD}

The purpose of QFD in this study was to transform CRs into specific plans to produce and meet those needs. The customers here are formwork workers, engineers, and field managers. To investigate the CRs, we used the IPA technique because we cannot improve all the requirements, so we prefer to improve the features with the highest priority.

\subsubsection{Deriving the TCs}

To analyze the correlation between the users' requirement qualities and the TCs of the system form, the CRs were analyzed in terms of their category and requirements. The TCs were derived by the same group of experts with more than 10 years of experience in form development, and 14 TCs were selected by deriving the TCs (Table 4).

\subsubsection{Correlation between CRs and TCs}

To convert the users' requirements (CRs) into TCs of the system form, we analyzed the correlations between the two parameters through the experts' group. Because the developer of the product has a high understanding of the TCs of the components and the operation process, the analysis was performed by the same expert group that derived the TCs. For the items with a correlation between the required quality and the TCs of the system form according to the QFD analysis method, correlation coefficients of 9 for high, 3 for normal, and 1 for weak were
Table 4. Related CRs for each of the TCs

\begin{tabular}{|l|l|l|}
\hline No. & \multicolumn{1}{|c|}{ TC } & \multicolumn{1}{c|}{ Related CRs } \\
\hline TC1 & Shape of the outer frame & $\begin{array}{l}\text { CR1, CR4, CR6, CR13, } \\
\text { CR14, CR15 }\end{array}$ \\
\hline TC2 & Weight & CR4, CR6 \\
\hline TC3 & Size & $\begin{array}{l}\text { CR1, CR4, CR13, CR14, } \\
\text { CR15 }\end{array}$ \\
\hline TC4 & Number of repeat uses & CR7, CR8, CR10 \\
\hline TC5 & Shape of the inner structure & CR5, CR9, CR10 \\
\hline TC6 & Assembly type & CR1, CR9, CR10 \\
\hline TC7 & Installation method & CR1, CR2, CR4 \\
\hline TC8 & Dismantlement method & CR1, CR2, CR4 \\
\hline TC9 & Impact resistance & CR7, CR8, CR9, CR10 \\
\hline TC10 & Allowable load & CR5, CR9 \\
\hline TC11 & Material of panel & $\begin{array}{l}\text { CR2. CR3, CR7, CR8, } \\
\text { CR10, CR11, CR12 }\end{array}$ \\
\hline TC12 & Material of frame & CR7, CR8, CR9, CR10 \\
\hline TC13 & Lifting method & CR4 \\
\hline TC14 & Structure of panel frame & CR2, CR10 \\
\hline
\end{tabular}

assigned to each correlation to differentiate the choices clearly (Cohen, 1995) (Table 5).

To calculate the weight of each TC reflecting the required quality following the correlation analysis, the absolute importance weight of the TC was multiplied by the correlation coefficient and the importance index of the required quality, as shown in Eqn (1) The relative weights were calculated by dividing the absolute weights by the sum of the absolute weights as shown in Eqn (2). The priority of each TC was determined, and the importance of each TC was quantitatively derived to improve the users' requirements.

Table 3. CRs - importance index score

\begin{tabular}{|c|c|c|c|c|}
\hline No. & Category & $\mathrm{CR}$ & Importance Index & Rank \\
\hline CR1 & \multirow{4}{*}{$\begin{array}{l}\text { Constructa- } \\
\text { bility }\end{array}$} & Easy assembly and disassembly (it fits and fastens together with reasonable ease) & 91.3 & 1 \\
\hline CR2 & & Reduced noise during dismantlement or assembly and disassembly & 87.4 & 2 \\
\hline CR3 & & Easy removal from concrete & 76.2 & 8 \\
\hline CR4 & & Efficient lifting and carrying & 79.6 & 6 \\
\hline CR5 & \multirow{2}{*}{ Safety } & Not distorted or deflected during concrete placing & 56.3 & 15 \\
\hline CR6 & & Reduced safety accident (struck by object) & 57.7 & 13 \\
\hline CR7 & \multirow{4}{*}{ Durability } & High repeat use with a constant module size & 83.2 & 4 \\
\hline CR8 & & Recyclable material usage & 61.4 & 12 \\
\hline CR9 & & Durable against falling and external impacts & 64.2 & 10 \\
\hline CR10 & & Easy maintenance and cleaning & 69.9 & 9 \\
\hline CR11 & \multirow{2}{*}{ Reliability } & Low thermal conductivity (low temperature sensitivity) & 59.1 & 14 \\
\hline CR12 & & High concrete surface quality & 78.8 & 7 \\
\hline CR13 & \multirow{3}{*}{ Conformance } & $\begin{array}{l}\text { Compatible (size, height, fixing method) with existing formwork units } \\
\text { (e.g., Al-form, Euro form, Skydeck) }\end{array}$ & 86.7 & 3 \\
\hline CR14 & & $\begin{array}{l}\text { Hybrid (concurrent usage) usage for vertical (wall and column) and horizontal } \\
\text { (slab) forms }\end{array}$ & 63.1 & 11 \\
\hline CR15 & & $\begin{array}{l}\text { Provide various module sizes to minimize on-site work } \\
\text { (filler, conventional formwork) }\end{array}$ & 81.9 & 5 \\
\hline
\end{tabular}


Table 5. A calculation matrix for absolute and relative weights between TCs and CRs

\begin{tabular}{|c|c|c|c|c|c|c|c|c|c|c|c|c|c|c|c|}
\hline \multicolumn{2}{|c|}{ CRs $\mathrm{TCs}$} & TC1 & TC2 & TC3 & TC4 & TC5 & TC6 & TC7 & TC8 & TC9 & TC10 & TC11 & TC12 & TC13 & TC14 \\
\hline CR1 & 91.3 & 9 & 9 & 9 & & 9 & 9 & 9 & 9 & & & & & & 3 \\
\hline CR2 & 87.4 & & 9 & & & & & 9 & 9 & & & 9 & 9 & & 3 \\
\hline CR3 & 76.2 & & & & & & & & 3 & & & 9 & & & \\
\hline CR4 & 79.6 & 3 & 9 & 3 & & 1 & & 3 & & & & & & 9 & \\
\hline CR5 & 56.3 & & & & & 3 & & & & & 9 & & 9 & & \\
\hline CR6 & 57.7 & 1 & 9 & 3 & & & & 3 & 3 & & & & & & \\
\hline CR7 & 83.2 & & & & 9 & & & & & 9 & & 9 & & & \\
\hline CR8 & 61.4 & & & & 9 & & & & & & & 9 & & & \\
\hline CR9 & 64.2 & & 3 & 1 & & 3 & 9 & & 3 & & 9 & & 9 & & 3 \\
\hline CR10 & 69.9 & & & & 9 & 3 & 9 & & & 9 & & 9 & 3 & & 3 \\
\hline CR11 & 59.1 & & & & & & & & & & & 9 & 3 & & \\
\hline CR12 & 78.8 & & & & & & & & & & & 9 & & & \\
\hline CR13 & 86.7 & 9 & & 9 & & & & 3 & 3 & & & & & & 3 \\
\hline CR14 & 63.1 & 1 & & 3 & & & & 3 & 3 & & & & & & \\
\hline CR15 & 81.9 & 3 & & 1 & & & & 3 & 3 & & & & & & \\
\hline $\begin{array}{r}\text { Abs } \\
\text { we }\end{array}$ & & 2.209 & 3.036 & 2.351 & 1.926 & 1.469 & 2.025 & 2.712 & 2.892 & 1.377 & 1.080 & 4.633 & 2.250 & 720 & 1.197 \\
\hline $\begin{array}{r}\text { Rel } \\
\text { weigl }\end{array}$ & $\begin{array}{l}\text { ive } \\
(\%) \\
\end{array}$ & 7.39 & 10.16 & 7.87 & 6.45 & 4.92 & 6.78 & 9.08 & 9.68 & 4.61 & 3.61 & 15.51 & 7.53 & 2.41 & 4.01 \\
\hline $\mathrm{Ra}$ & & 7 & 2 & 5 & 9 & 10 & 8 & 4 & 3 & 11 & 13 & 1 & 6 & 14 & 12 \\
\hline
\end{tabular}

Absolute weight $=$

$\sum$ Importance Index $\times$ Correlation coefficient;

Relative weight $=$

$\frac{\text { Absolute weight of technical characteristic }}{\sum \text { Absolute weight of technical characteristics }} \times 100$.

The panel material of the system form (TC11) was ranked as the most important TC, followed by the form weight (TC2), the installation/dismantling method (TC7, TC8), size (TC3), and the frame material (Table 5). Thus, in this study, these technical features were selected as the main required TCs, and the improvement step considering the correlation of the TCs was performed with these characteristics.

\subsubsection{Contradictions check between TCs}

For the mutual analysis of required TCs, an HOQ roof TCs correlation table was used. From the expert group's analysis, the TCs of the negative correlations were expressed as technical contradictions of the requirements (Figure 5). The negative correlation means that there is an inverse relationship between two variables: i.e., when one TC increases, the other decreases. Through this check, the optimal development direction that minimizes the sacrifice between TCs can be derived. (C1) If the external frame form (TC1) or size (TC3) are changed for easy assembly/

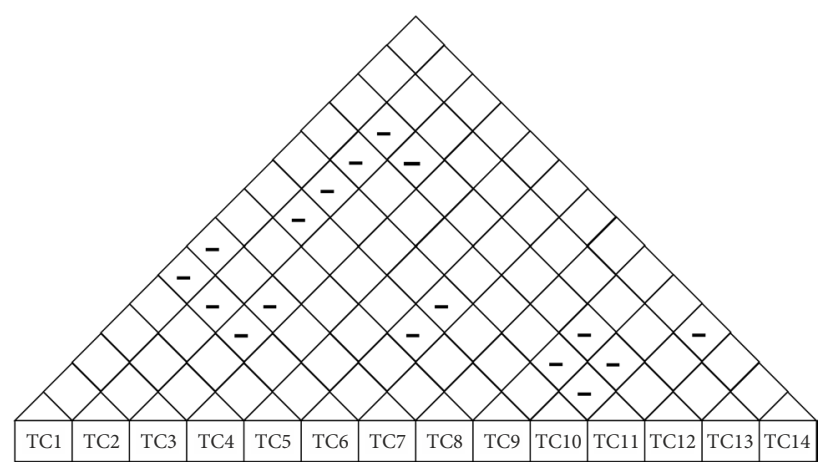

Figure 5. Contradiction check between TCs

disassembly, the existing forms and the installation and disassembly methods (TC6, TC7) become incompatible.

(C2) If the materials of panel and frame (TC11, TC12) are changed to reduce noise, there is a contradiction on the impact strength (TC9), allowable load (TC10), and weight (TC2).

(C3) Reducing the weight of the form (TC2) for easy assembly and disassembly and efficient lifting and carrying may cause inconsistencies in terms of impact strength (TC9) and allowable load (TC10).

(C4) If the assembly type (TC6) is changed to bolt assembly instead of welding for noise reduction and easy maintenance, there are inconsistencies in terms of impact resistance (TC9) and allowable load (TC10). 
Table 6. Conversion of the improvement objects into TRIZ standard features

\begin{tabular}{|c|c|l|c|l|}
\hline Contradiction & Improvement objects & \multicolumn{1}{|c|}{ Converted TRIZ features } & Deteriorating objects & \multicolumn{1}{|c|}{ Converted TRIZ features } \\
\hline C1 & TC1, TC3 & 39. Productivity & TC6, TC7 & 35. Adaptability \\
\hline C2 & TC11, TC12 & 31. Harmful side effects & TC9, TC2, TC10 & 13. Stability of object \\
\hline C3 & TC2 & 39. Productivity & TC9, TC10 & 35. Adaptability \\
\hline C4 & TC6 & 34. Repairability & TC9, TC10 & 14. Strength \\
\hline C5 & TC11 & 27. Reliability & TC4 & 25. Loss of time \\
\hline
\end{tabular}

(C5) To improve the quality of the concrete installation surface, there is a contradiction between the panel material changes (TC4), reuse rate (TC11), and increased workload (time loss).

\subsubsection{Conversion into standard characteristics}

To use the contradiction matrix table for the four contradictory relations derived, it must be converted into the standard form of the contradiction matrix. The characteristics that improve the contradiction relations and the characteristics that deteriorate while trying to improve others were compared with the 39 standard characteristics of the contradiction matrix and converted into standard matching or related features (Table 6).

\subsection{Analyze: TRIZ}

\subsubsection{Principle of invention}

To solve the technical contradiction problem between the standard characteristics, the standard features of the contradictory relation were applied to the contradiction matrix, and the principle of invention corresponding to each intersection point was derived (Table 7). Afterward, according to the contradiction and 40 invention principles of TRIZ, a new idea was developed for the concrete form.

\subsubsection{Deriving design ideas using inventive principles}

Among the inventive principles derived from the solutions corresponding to each contradiction, ideas were derived

Table 7. Deducing the principle of invention of TRIZ

\begin{tabular}{|c|c|c|c|c|c|}
\hline & 2 & 13 & 14 & 32 & 25 \\
\hline 6 & $\begin{array}{c}30,2, \\
14,18\end{array}$ & 2,38 & 40 & $\underline{\mathbf{4 0 ,} \mathbf{1 6}}$ & $\begin{array}{c}10,35,4, \\
18\end{array}$ \\
\hline 27 & $\begin{array}{c}3,10,8, \\
28\end{array}$ & - & 11,28 & - & $\underline{\mathbf{1 0 , 3 0 , 4}}$ \\
\hline 31 & $\underline{\mathbf{3 5 , 2 2}, \mathbf{3 0}}$ & $\begin{array}{c}35,40, \\
27,39\end{array}$ & $\begin{array}{c}15,32, \\
22,2\end{array}$ & - & 1,22 \\
\hline 34 & $\begin{array}{c}2,27, \\
35,11\end{array}$ & $\underline{\mathbf{2 , 3 5}}$ & $\begin{array}{c}1,11, \\
2,9\end{array}$ & $\begin{array}{c}1,35, \\
11,10\end{array}$ & $\begin{array}{c}32,1,10, \\
25\end{array}$ \\
\hline 39 & $\begin{array}{c}28,27, \\
15,3\end{array}$ & $\begin{array}{c}35,3, \\
22,39\end{array}$ & $\begin{array}{c}\underline{\mathbf{2 9}, \mathbf{2 8},} \\
\mathbf{1 0 , 1 8}\end{array}$ & $\begin{array}{c}35,28, \\
2,24\end{array}$ & - \\
\hline
\end{tabular}

using inventive principles suited to the design of the system formwork. Through inventive principles, we found common solutions and ideas through recursive thinking by referring to existing cases through solutions (Table 8). For example, to solve the contradiction of changing the size or shape of the system form - contradiction $\mathrm{C} 1$, in which compatibility with the existing system forms is reduced - we divided the object into parts. Then, by separating the outer frame and the inner frame and the panel, compatibility with the existing system form was ensured, and productivity could be improved by reducing the weight.

All four principles of invention - segmentation, composite materials, prior compensation, and flexible membranes/thin films - were applied to improve the system form (Table 9).

\section{Design and validation}

\subsection{New composite system form design}

A new composite system form (CSF) was designed using the idea derived from Table 9. The geometry of each part of the CSF was not yet optimized, in order to see only the effects of the new material combination. The five parts were newly designed with differentiation from the existing form.

The proposed new system form (CSF) comprises an outer frame made of an aluminum-magnesium alloy and an inner frame made of steel (Figure 6). The composite form $(12.9 \mathrm{~kg})$ is at least $14 \%$ lighter than the existing system form (aluminum and Euro form); thus, it is easy to handle and efficient to install and dismantle, improving the productivity of formwork. The low weight of the form greatly reduces the workload in the construction process and guarantees high efficiency in the transportation of materials because greater amounts can be stacked in a truck or stockyard. In addition, by using separate components in place of the integral structure, it is possible to simultaneously solve noise problems (below $105 \mathrm{~dB}$, $120 \mathrm{~dB}$ on $\mathrm{Al}$-form), panel replacement problems, and the use of a stripping agent - all of which are issues with existing system forms - while ensuring compatibility with existing frames. 
Table 8. Idea development based on general solutions of TRIZ

\begin{tabular}{|c|l|l|l|}
\hline Contradiction & Invention principle & \multicolumn{1}{|c|}{ General solutions } & \multicolumn{1}{|c|}{ Idea development } \\
\hline C1 & 1. Segmentation & $\begin{array}{l}\text { Divide an object into independent parts } \\
\text { Make an object sectional, easy to assemble/ } \\
\text { disassemble } \\
\text { Increase the degree of fragmentation of } \\
\text { segmentation }\end{array}$ & $\begin{array}{l}\text { The forms frame can be divided into three } \\
\text { main parts (inner, outer, and panel) to } \\
\text { reduce the weight of forms, avoid usage of } \\
\text { form oil, and ease maintenance }\end{array}$ \\
\hline C2 & $\begin{array}{l}\text { 40. Composite } \\
\text { materials }\end{array}$ & $\begin{array}{l}\text { Change from uniform to composite (multiple) } \\
\text { materials }\end{array}$ & $\begin{array}{l}\text { composite-based noise-reducing materials } \\
\text { (joint apparatus) are used }\end{array}$ \\
\hline C3 & $\begin{array}{l}\text { 40. Composite } \\
\text { materials }\end{array}$ & $\begin{array}{l}\text { Change from uniform to composite (multiple) } \\
\text { materials }\end{array}$ & $\begin{array}{l}\text { Lightweight composite material } \\
\text { (aluminum and magnesium composite) } \\
\text { frames can be used }\end{array}$ \\
\hline C4 & $\begin{array}{l}\text { 11. Prior } \\
\text { compensation }\end{array}$ & $\begin{array}{l}\text { Prepare emergency means beforehand to } \\
\text { compensate for the relatively low reliability of } \\
\text { an object }\end{array}$ & $\begin{array}{l}\text { Rubber-based impact-reducing materials } \\
\text { are used }\end{array}$ \\
\hline C5 & $\begin{array}{l}\text { 30. Flexible } \\
\text { films }\end{array}$ & $\begin{array}{l}\text { Use flexible shells and thin films instead of 3D } \\
\text { structures } \\
\text { Isolate the object from its external environment } \\
\text { using flexible membranes }\end{array}$ & $\begin{array}{l}\text { Very thin films are applied to avoid } \\
\text { attachment of concrete }\end{array}$ \\
\hline
\end{tabular}

Table 9. Improvement solution for concrete form according to the ideas

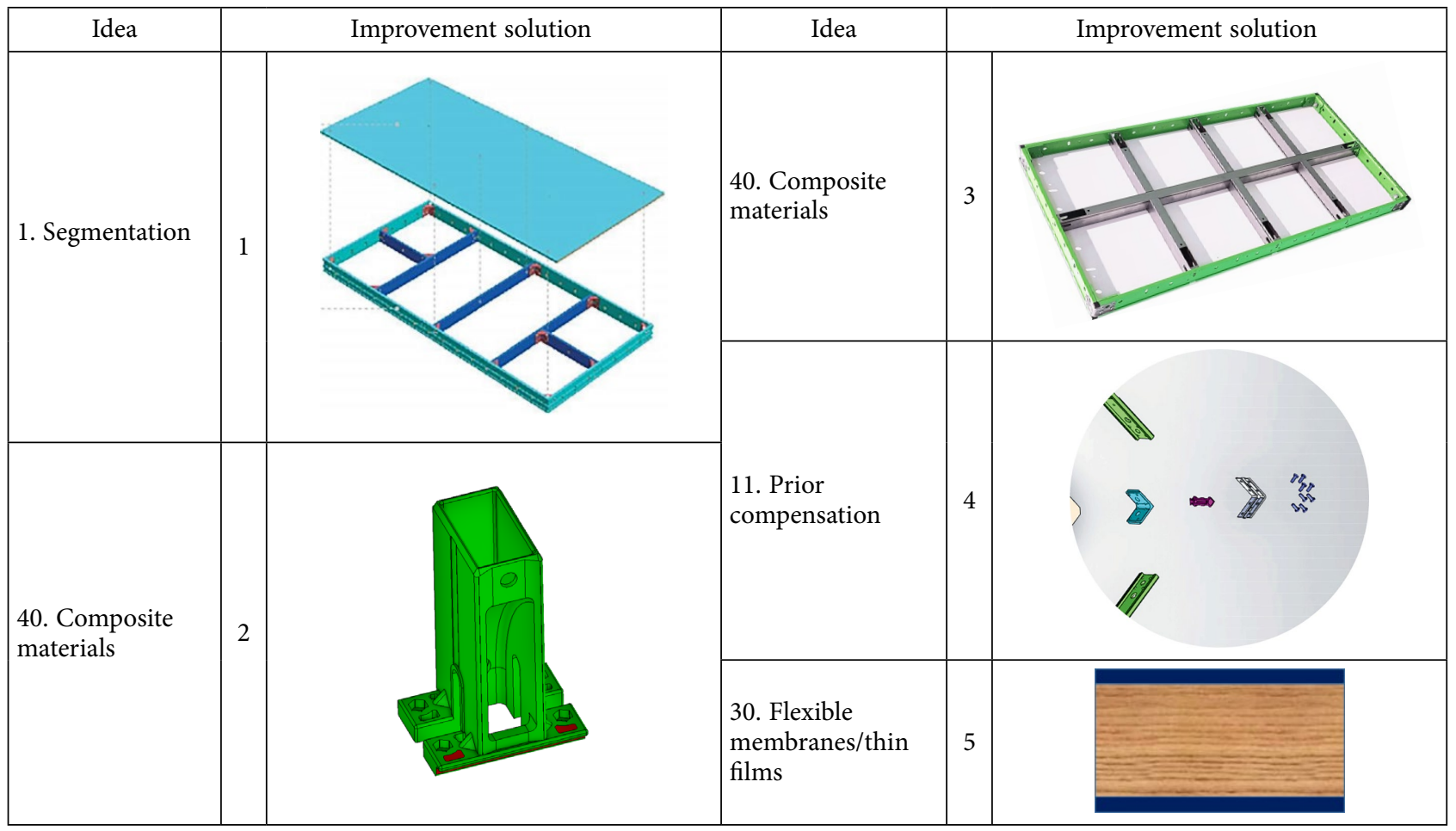

\subsection{Validation}

\subsubsection{Computer-aided engineering (structural safety)}

The structural analysis of the designed CSF system was performed using ABAQUS FEA software, and the result is shown in Figure 7. The deflection criterion for the hybrid form is not specified, but a system form standard requires the deflection of form within $3 \mathrm{~mm}$ in Korea when concrete is poured. In this study, the amount of deflection according to the load of $14,400 \mathrm{~N}$ was examined in the same manner as the Korea Standard (KS) F 8006. Once the first prototype was designed, structural reinforcement was conducted to reduce deflection. In the final prototype modeling, the deflection was approximately $1.123 \mathrm{~mm}$ on a load of $14,400 \mathrm{~N}$.

\subsubsection{Prototype verification}

The proposed system form was applied to two different construction projects to verify its applicability and effect. Before applying the form to the construction site, we verified its structural safety based on KS F 8006 because it is very strong verification of the structural safety of concrete forms. The satisfaction of KS F 8006 ensures the safety of formwork regardless of the application or location in Korea. 


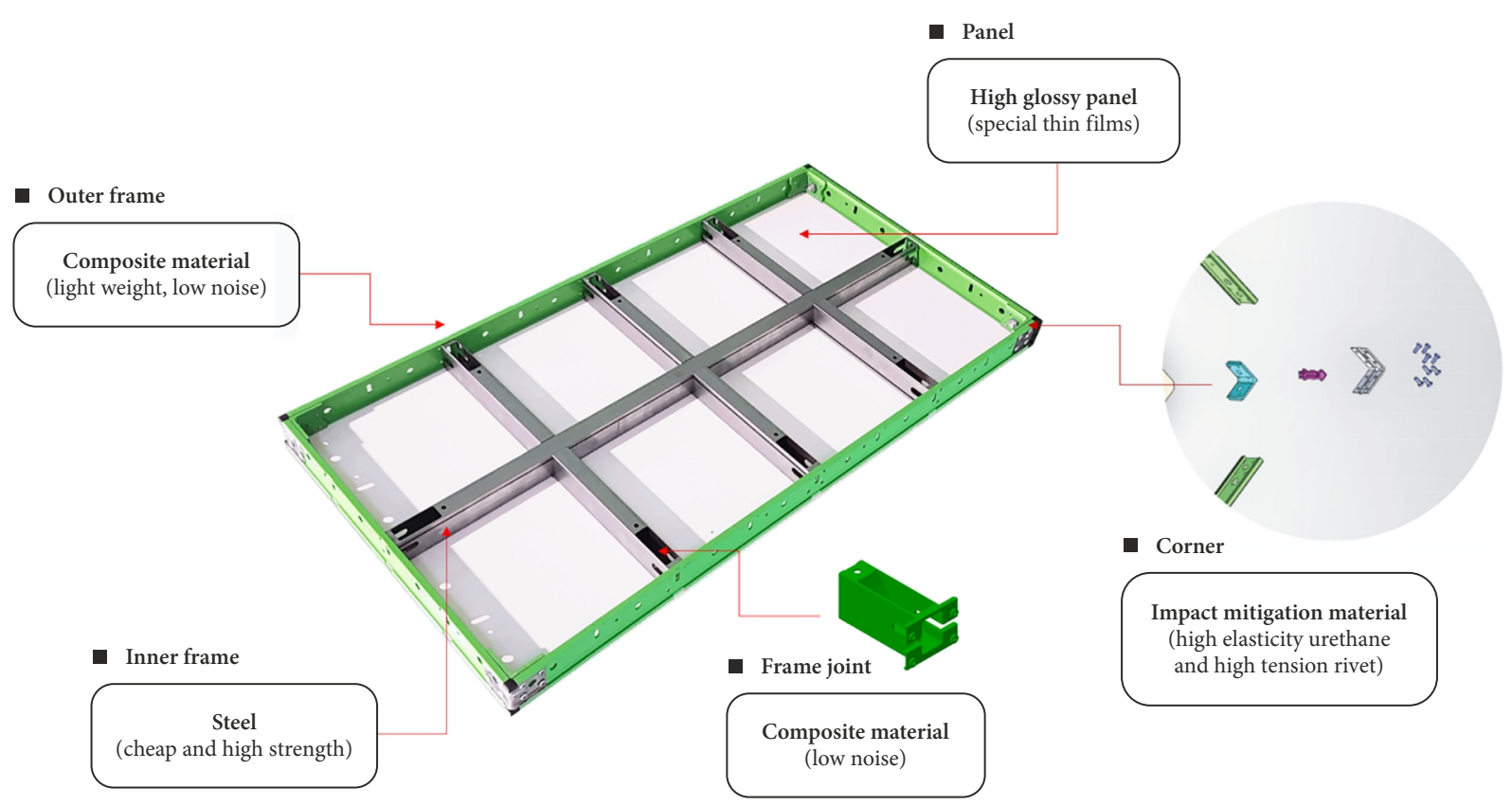

Figure 6. Idea combination for the CSF from the TRIZ inventive theory
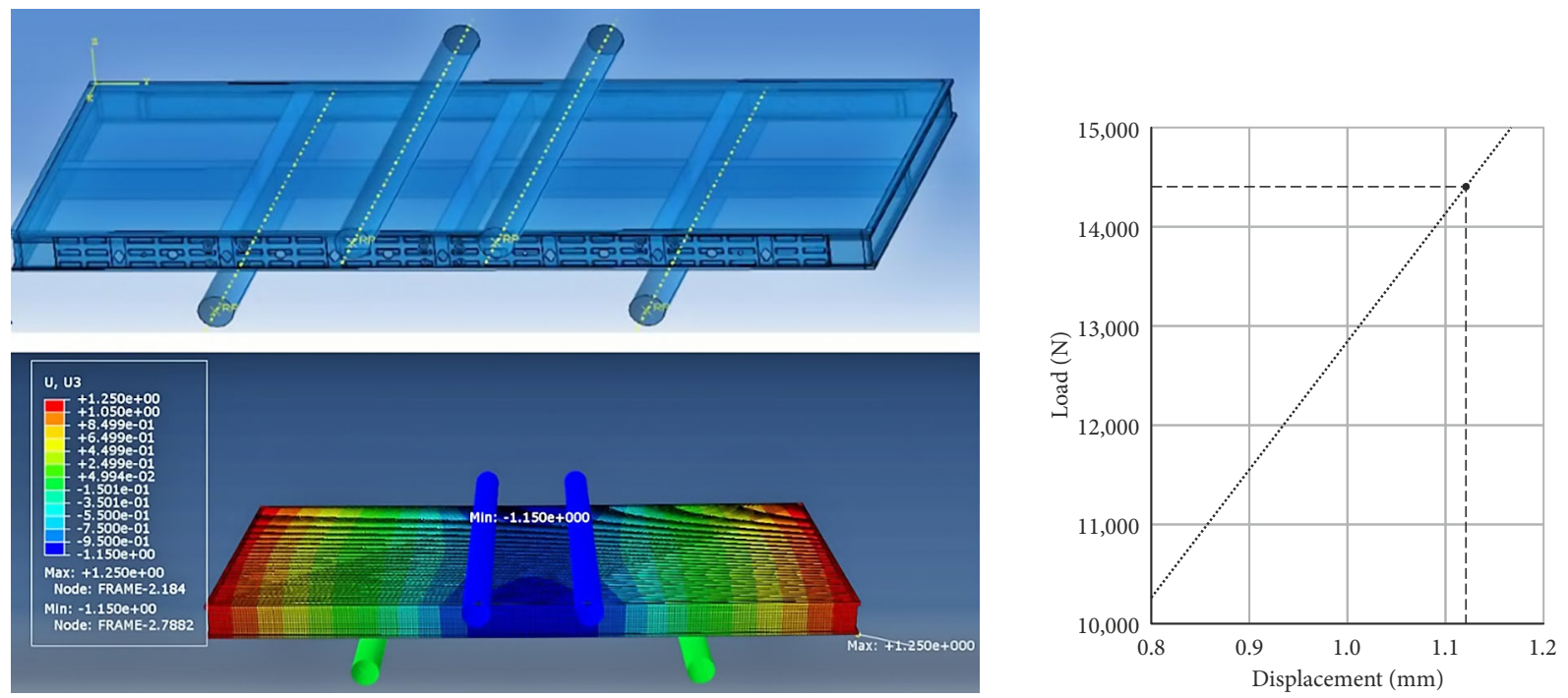

Figure 7. Structural analysis of prototype (deflection)

However, depending on the country, the frame size can be changed because the allowable deflection may differ. In this verification, the authors used the size of $600 \times$ $1200(\mathrm{~mm})$, which is the same as the existing Korean system form size. This weighs about $12.9 \mathrm{~kg}$, which is at least $14 \%$ lighter than the existing $\mathrm{Al}$ form $(15 \mathrm{~kg})$ and Euro form $(19 \mathrm{~kg})$.

\section{(1) CSF structural analysis (standard loading procedure)}

A standard loading test was performed on the fabricated CSF prototype to calculate the deflection of the form. The loading method is described in Figure 8, and the maximum load $(\mathrm{P})$ was 1.5 tons. If the deflection on the load is less than $1.4 \mathrm{~mm}$, it satisfies the KS standard, and this means that it is structurally safe during concrete casting in a normal place at a construction site.

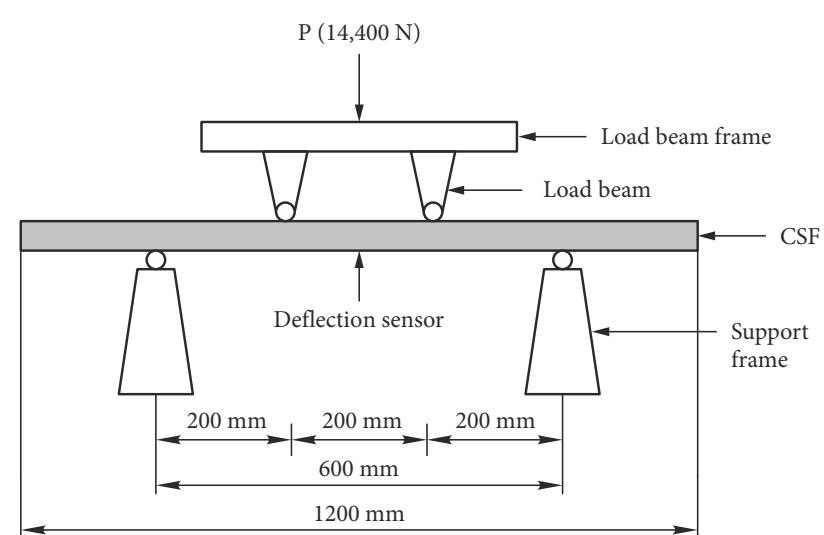

Figure 8. KS F 8006 (standard loading method for concrete form in Korea) 
As a result of three measurements, the average deflection of CSF was less than $1.4 \mathrm{~mm}$, meaning that it satisfies KS F 8006.

\section{(2) Recycle time test}

If a form can be used without replacing the panel, we can save much time and effort; therefore, as the recycle time increases, the productivity of form improves. In addition, CSF is composed of an assembly structure, and the panel can be independently changed for avoiding replacement of the entire form. In the present study, test to determine the number of recycles without needing to be replace was performed for a thin-film coated wood panel. Because there is no official certification test for the number of reuses of the form, the evaluation was performed subjectively by comparing the change of the surface of the panel and the surface of the concrete after removing the concrete. The test results are shown in Figure 9. During the 50 experiments, the panel surface or concrete surface was maintained at the highest quality.

\section{(3) Noise test}

In this study, two noise tests were conducted to measure the noise of CSF. One test examined the noise generated when dropping CSF at a height of $3.5 \mathrm{~m}$, while the other examined the noise generated during the installation and dismantling of pins by a hammer. The average values were measured after four tests. For a comparison with the existing form, the same experiment was performed on the Al-form and Euro forms. The measurement results are shown in Figure 10. CSF absorbs noise through shock absorbing and separate frame structures, resulting in less noise than other forms ( $16.875 \mathrm{~dB}$ was reduced compared to Al-form during installation).

\section{(4) Application for table form}

Because the CSF is a modular form, it offers customizable size and shape for a table form method (Figure 11) with a large flat surface in a flat plate slab structure and a high floor height building. Because the table form construction is highly safe and because the assembly and disassembly of the formwork can be performed mechanically and quickly, the developed form can be used when using the table form method on a site.

The size of the CSF module table form can be decided according to the shape of the floor. The length of the floor can be $1,200,1,800,2,400,3,000,3,600$, or $4,200(\mathrm{~mm})$; and the width can be $1,800,2,400,3,000,3,600,4,200$, or $4,800(\mathrm{~mm})$. The assembly units consist of form panel units, beam, brackets, and shores (Figure 11). To check the safety of the table, we conducted computer analysis when pouring concrete on the table form.

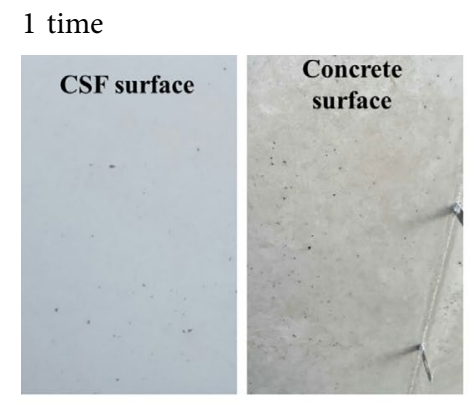

20 times

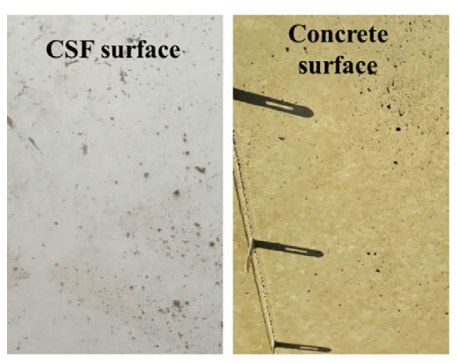

40 times

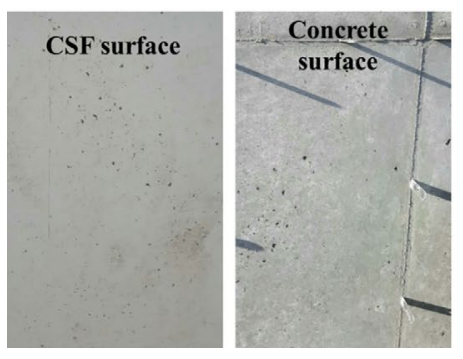

10 times

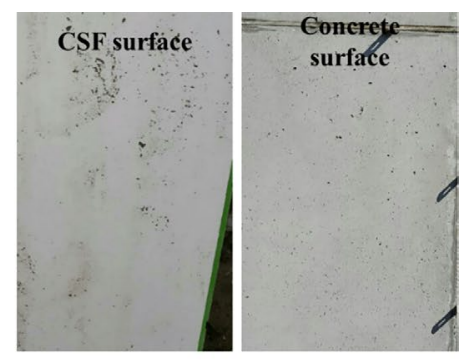

30 times

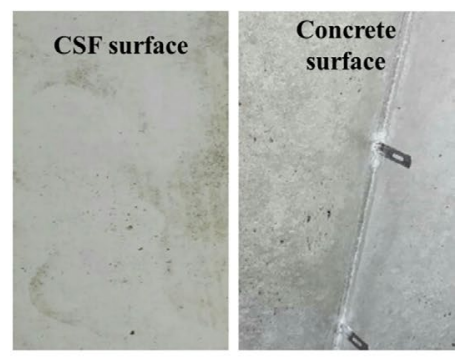

50 times

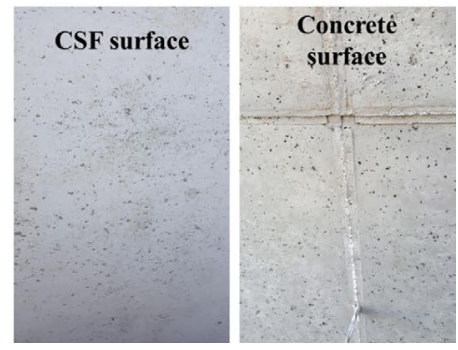

Figure 9. Concrete surface and formwork surface test 


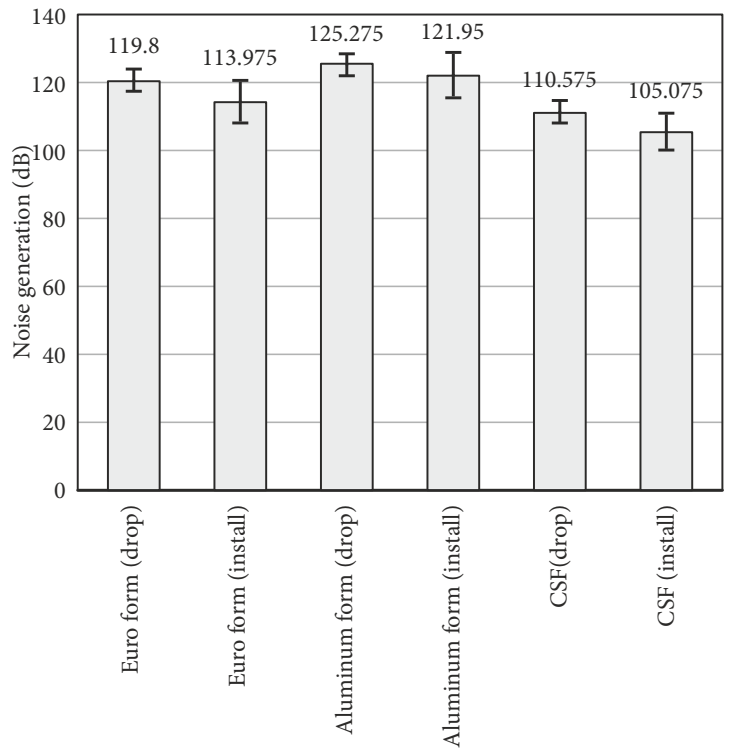

Figure 10. The results of noise generation

\section{(5) Field application of CSF and its table form (slab)}

The assembled CSF and its table form were applied to a construction site (Figure 12) to test on-site applicability and safety. The test was conducted for months, and a total of 100 CSF form units were applied as both CSF and CSF tables.

\section{(6) Satisfaction survey (subjective evaluation)}

$84 \%$ of form users who participated in the survey ( 42 experts in total) were satisfied with the technicality of the
CSF, and they said the CSF would be more productive than the Al-form and Euro form (Figure 13).

(7) CR satisfaction score comparison (quantitative evaluation)

A CR satisfaction score (CRSS) was newly defined to compare customer satisfaction between the forms quantitatively. The evaluation was conducted by surveying 10 workers who used all the forms; i.e., the developed CSF, $\mathrm{Al}$-form, and Euro form, at the same time. A five-point Likert scale that ranges from "extremely satisfied" to "not at all satisfied" was used for three different forms. The mean value of each satisfaction score for $15 \mathrm{CRs}$ was calculated, and the CRSS was calculated by multiplying by the importance index, as shown in Table 10 and Figure 14.

\subsection{Results}

The CSF was compared with the existing system forms, $\mathrm{Al}$-form and Euro form, and the following results were obtained (Table 11):

1. CSF is structurally safe during and after casting concrete and even has a reduced weight $(12.9 \mathrm{~kg})$.

2. CSF secures the high-quality concrete surface because the panel does not stick to concrete because of the laminate film coating on the panel, and its number of recycles is higher than the Euro form (less than 10 times) and the same as the Al-form (above 50 times). In addition, the use of CSF does not require form oil before concrete casting, which helps reduce the cost and duration.
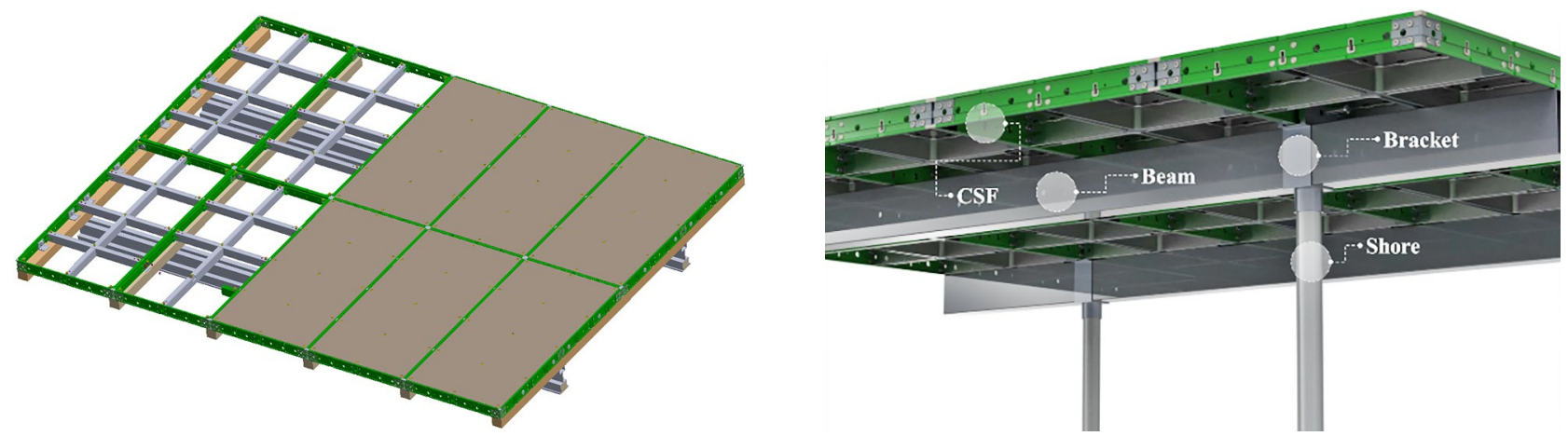

Figure 11. 3D drawing of CSF table form (slab)
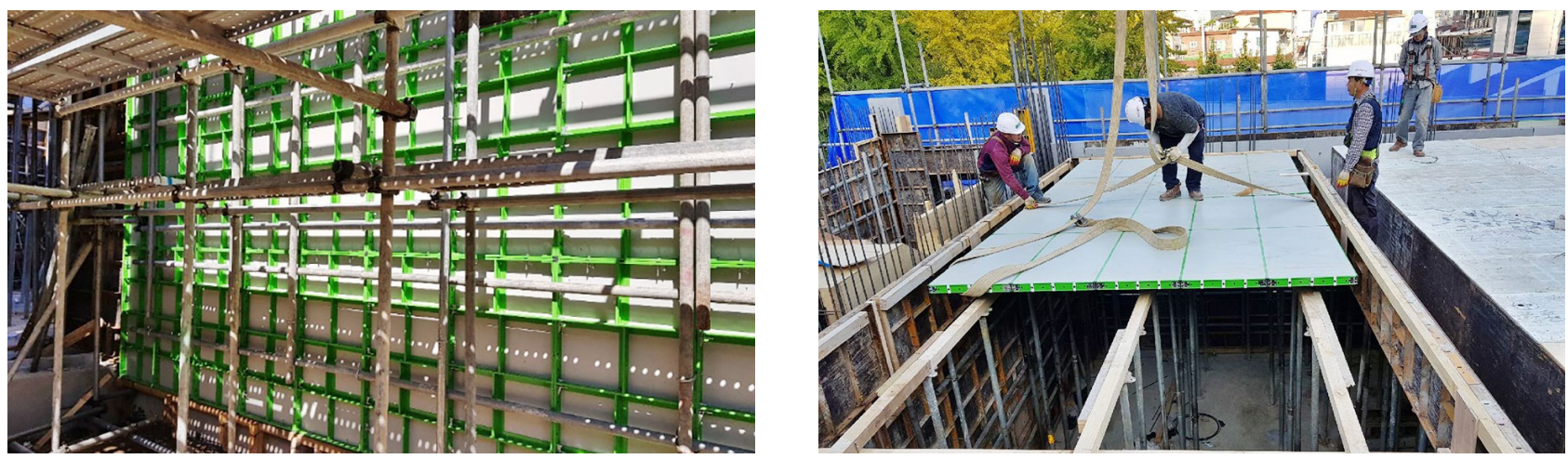

Figure 12. Field application of CSF and its table form (slab) 


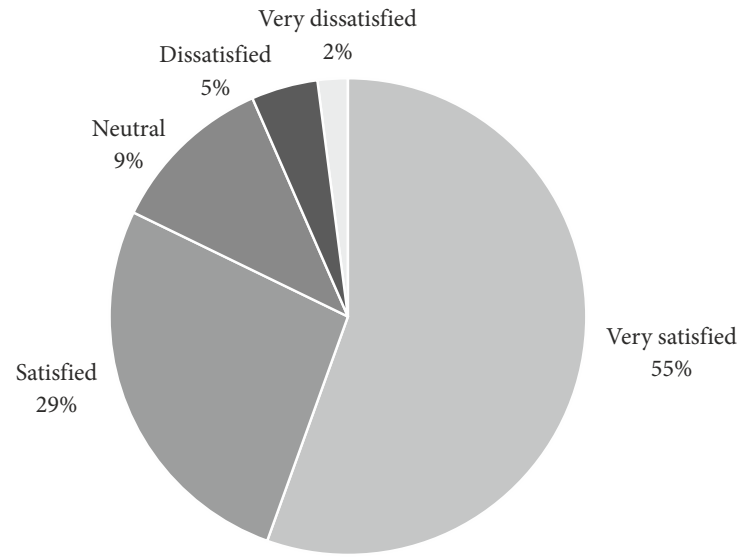

Figure 13. User satisfaction for the new system form, CSF

3. CSF reduces the noise caused during installation/dismantlement or from dropping the form from a high position (compared to Al-form, the noise was reduced by $-14.7 \mathrm{~dB}(-1.850 \%)$ during the drop and $-16.875 \mathrm{~dB}$ $(-2.124 \%)$ during the installation / disassembly work).

4. The separated structure between the frame and panel makes maintenance work easy because it can be replaced if there is damage in any part separately.

5. Prior compensation at the corner reduces the impact and noise when dropping from a high place, and it reduces the chance of severe accident by struck.

6. A total of $84 \%$ of CSF users were satisfied with the performance of the CSF in a survey.

7. In the total CRSS section, CSF scored 4,586.5, Al-form scored 3,757.72, and Euro form scored 3,147.56.

8. Except for CR8 (Recyclable material usage) and CR15 (Provide various module sizes), which can be solved in mass production, the newly developed CSF shows higher satisfaction results than the Al-form and Euro form.

9. In particular, CSF shows superior performance compared to existing technologies in terms of CR2 (Reduced noise), CR7 (High repeat use), and CR13 (Compatible with existing formwork units).
Table 10. CRS comparison between forms

\begin{tabular}{|c|c|c|c|c|c|c|c|}
\hline 怘 & $\tilde{\omega}$ & $\frac{\Xi}{0}$ & 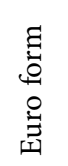 & 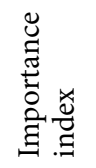 & $\begin{array}{l}\mathscr{A} \\
\mathscr{U}\end{array}$ & 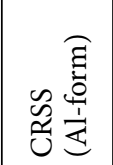 & 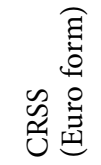 \\
\hline CR1 & 4.6 & 4 & 2.9 & 91.3 & 420.0 & 365.2 & 264.8 \\
\hline CR2 & 4 & 1.2 & 2.1 & 87.4 & 349.6 & 104.9 & 183.5 \\
\hline CR3 & 4.6 & 4.2 & 3.5 & 76.2 & 350.5 & 320.0 & 266.7 \\
\hline CR4 & 4.4 & 4.1 & 2.2 & 79.6 & 350.2 & 326.4 & 175.1 \\
\hline CR5 & 5 & 5 & 5 & 56.3 & 281.5 & 281.5 & 281.5 \\
\hline CR6 & 4.2 & 3 & 2.1 & 57.7 & 242.3 & 173.1 & 121.2 \\
\hline CR7 & 4.9 & 4.2 & 1.2 & 83.2 & 407.7 & 349.4 & 99.8 \\
\hline CR8 & 3.8 & 4.7 & 3 & 61.4 & 233.3 & 288.6 & 184.2 \\
\hline CR9 & 3.9 & 3 & 3.1 & 64.2 & 250.4 & 192.6 & 199.0 \\
\hline CR10 & 3.7 & 1.7 & 3.2 & 69.9 & 258.6 & 118.8 & 223.7 \\
\hline CR11 & 3.9 & 1.2 & 3.2 & 59.1 & 230.5 & 70.9 & 189.1 \\
\hline CR12 & 4.5 & 4.1 & 3.3 & 78.8 & 354.6 & 323.1 & 260.0 \\
\hline CR13 & 5 & 3 & 3 & 86.7 & 433.5 & 260.1 & 260.1 \\
\hline CR14 & 3.6 & 3.4 & 2.8 & 63.1 & 227.2 & 214.5 & 176.7 \\
\hline CR15 & 2.4 & 4.5 & 3.2 & 81.9 & 196.6 & 368.6 & 262.1 \\
\hline Total & 62.5 & 51.3 & 43.8 & 1096.8 & 4586.5 & 3757.72 & 3147.56 \\
\hline
\end{tabular}

\subsection{Discussion}

The DFSS consisting of QFD and TRIZ provided a useful solution for new concrete form development with systematic scientific approaches reaching optimal performance (weight, cost, noise generation, and environmental issues). These approaches can be very useful in construction sites because many works are performed simultaneously. If a product designer thinks about only one work task during product development, other works may be negatively affected. The DFSS provides an optimal strategy to improve the overall performance of the entire team based on the requirements and technical characteristics of each work.

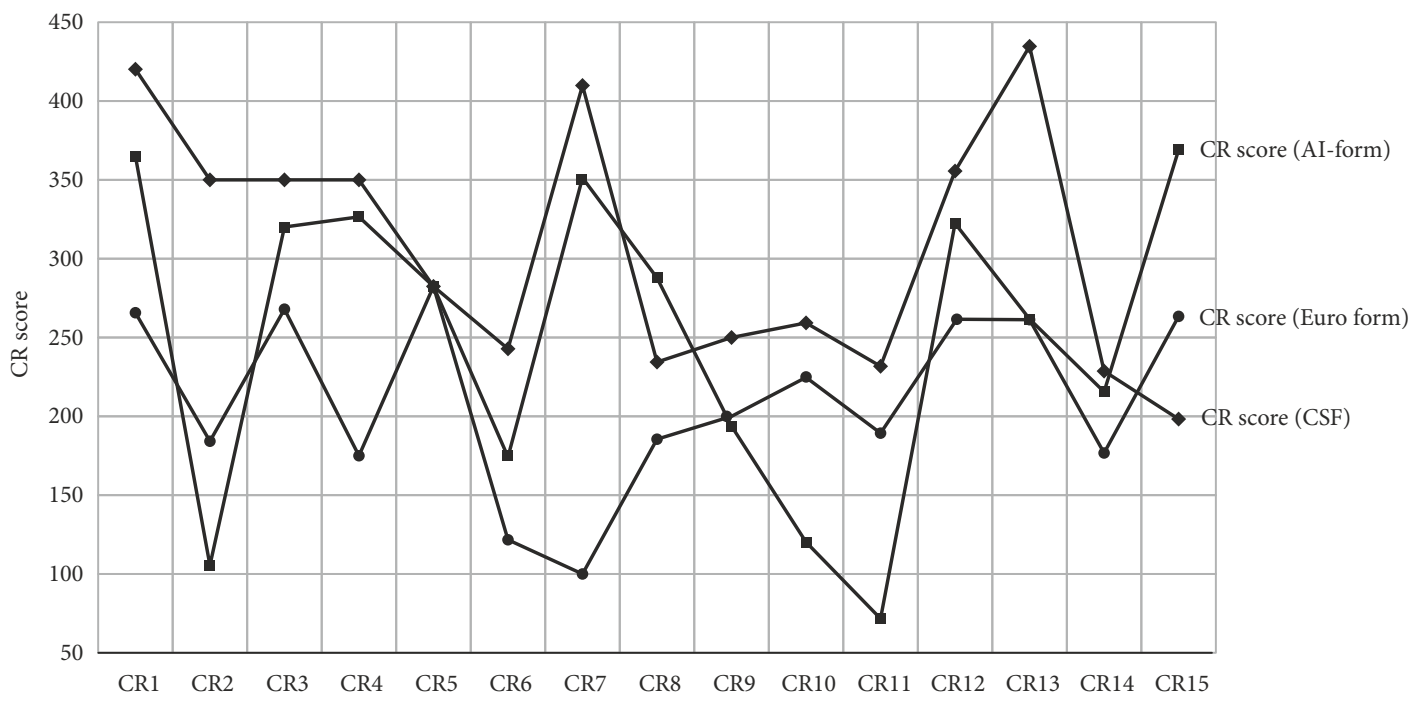

Figure 14. CR satisfaction score for CSF, Al-form and Euro form 
The present study attempted an approach applying different combinations and choices in terms of materials for each section of the formwork to solve previous formwork problems and proved that the approach is a great solution. The major improvements as a result of using composite material are as follows.

First, reducing the weight of the formwork can reduce the labor load of workers and improve productivity. For example, wall formwork assembly, which previously had to be performed by two people, can be performed by one worker. In addition, the lighter weight makes it easier to assemble large system forms, such as table and gang forms that are equipment-driven methods, so there could be a good synergy when applying construction machinery and IoT technology.

Second, CSF does not require any release agent before and during concrete casting, and it has a great advantage in terms of environmental issues. Because the release agent usually uses waste oil, it causes a large problem in environmental destruction and requires additional labor to apply the release agent. In addition, the quality of the concrete surface is very even and uniform, and these characteristics are very advantageous for construction with exposed concrete surfaces.

Third, the CSF, which consists of several parts, has the advantage of being able to be replaced by parts in case of breakage, which is advantageous in terms of maintenance.

Fourth, CSF can reduce noise generation. Noise generation during assembly or disassembly and falling is a large issue in the urban city area. Noise from the construction site creates a large amount of stress for workers and residents, and residents' civil petitions cause construction delays.

\section{Conclusions}

This study proposed a new composite material-based system form for building construction through a DFSS process including QFD and TRIZ to improve formwork productivity. After defining the goal statement of the new composite form, an IPA survey was conducted to obtain CRs and their priorities. Then, QFD methodology was used to translate the CRs to TCs, and TRIZ methodology was used to apply innovative principles that solve the contradiction matrix of TCs. The TRIZ general innovative principles were systematically integrated and prototyped, and then tested at a construction site to verify the productivity and constructability of the new composite form.

The CSF is composed of several separated design parts: outer frames, inner frames, and panels; and each component uses different materials to maximize performance. The integrated design process of DFSS provided a useful and general direction of thinking, thereby reducing the trial-and-error approach and generating high-quality ideas in less time than heuristic product design processes.

The purpose of this study was to solve previous formwork issue such as heavy weight, noise generation, cost overrun and environment issue enough for satisfying the workers. The proposed CSF is $14 \%$ lighter than the conventional $\mathrm{Al}$-form $(15 \mathrm{~kg})$ and $32 \%$ lighter than the Euro form $(19 \mathrm{~kg})$, and the noise level $(105-110 \mathrm{~dB})$ during installation and dismantling is remarkably reduced (the noise level while using Al-form is $122-125 \mathrm{~dB}$ ). In addition, CSF does not require a releasing agent, is easy to maintain, and can be used by a large-sized table formwork method by assembling two or more CSFs because

Table 11. Comparison between the CSF, Al-form, and Euro form

\begin{tabular}{|c|c|c|c|}
\hline Item & Composite system form (CSF) & Al-form & Euro form \\
\hline Material & $\begin{array}{l}\text { Composite (Aluminum + Magnesium) + } \\
\text { steel + Film coated plywood panel }+ \\
\text { rubber corner }\end{array}$ & $100 \%$ of Aluminum & Steel + Coated plywood \\
\hline \multicolumn{4}{|l|}{ Image } \\
\hline Specification & $600 \mathrm{~mm} \times 1.200 \mathrm{~mm}$ & $600 \mathrm{~mm} \times 1.200($ or 2.400$) \mathrm{mm}$ & $600 \mathrm{~mm} \times 1.200 \mathrm{~mm}$ \\
\hline Weight & $12.9 \mathrm{~kg}$ & $15 \mathrm{~kg}$ (or $30 \mathrm{~kg})$ & $19 \mathrm{~kg}$ \\
\hline $\begin{array}{l}\text { Number } \\
\text { of cycles }\end{array}$ & Above 50 times & Above 50 times & Below 10 times \\
\hline Use of form oil & None & Use & Use \\
\hline Noise creation & Below $105 \mathrm{~dB}$ & Above $120 \mathrm{~dB}$ & Above $110 \mathrm{~dB}$ \\
\hline CRSS & $4,586.5$ & $3,757.7$ & $3,147.6$ \\
\hline
\end{tabular}

Note: Image source: MIK Materials (2020). 
of their light weight and high compatibility. These advantages show that an application of composite material based new system can improve the productivity and quality of construction.

We found that the completed system form was highly satisfactory for workers compared with existing forms, and thus, represents a new direction to improve system forms. Improvement of the system formwork is expected to contribute greatly to improvements at construction sites, such as shortened construction period, cost reduction, noise reduction, accident prevention, and improved work environment. If the DFSS process integrating QFD and TRIZ is applied to system designs in other areas of building construction where various construction and technology methods are combined, it may be possible to derive a more creative improvement plan reflecting users' requirements.

\section{Funding}

This research was supported by a grant (19AUDPB106327-05) from the Architecture \& Urban Development Research Program funded by the Ministry of Land, Infrastructure and Transport of the Korean Government and (2016R1A2B3015348) from the National Research Foundation of Korea grant funded by the Korean government.

\section{Author contributions}

Dongmin Lee and Taehoon Kim design the research process using QFD and TRIZ and wrote the draft of the manuscript. Dongyoun Lee and Hyunsu Lim collected the customer requirements data and analyzed it. Taehoon Kim and Kyung-In Kang wrote final manuscript. All authors contributed to the analysis of the data and read the final paper.

\section{Disclosure statement}

The authors declare no disclosure statement

\section{References}

Akao, Y., King, B., \& Mazur, G. H. (1990). Quality function deployment: Integrating customer requirements into product design. Productivity Press.

Altshuller, G. (2002). 40 principles: TRIZ keys to innovation (Vol. 1). Technical Innovation Center, Inc.

Chang-Yeob, S., Hwan-Cheol, L., So-Hyun, P., Kyu-Man, C., \& Chang-Taek, H. (2010). Productivity analysis of structural work for apartment building using AL-Form TT. Structure \& Construction, 26(4), 113-121.

Cohen, L. (1995). Quality function deployment: How to make QFD work for you. Prentice Hall.

De Feo, J., \& Bar-El, Z. (2002). Creating strategic change more efficiently with a new design for six sigma process. Journal of Change Management, 3(1), 60-80.

https://doi.org/10.1080/714042521
El-Sharkawy, A., Salahuddin, A., \& Komarisky, B. (2014). Design for six sigma (DFSS) for optimization of automotive heat exchanger and underhood air temperature. SAE International Journal of Materials and Manufacturing, 7(2), 256-261. https://doi.org/10.4271/2014-01-0729

Fazeli, M., Florez, J. P., \& Simão, R. A. (2019). Improvement in adhesion of cellulose fibers to the thermoplastic starch matrix by plasma treatment modification. Composites Part B: Engineering, 163, 207-216.

https://doi.org/10.1016/j.compositesb.2018.11.048

Fey, V., \& Rivin, E. (2005). Innovation on demand: New product development using TRIZ. Cambridge University Press. https://doi.org/10.1017/CBO9780511584237

Fung, R. Y. K., Chen, Y., Chen, L., \& Tang, J. (2005). A fuzzy expected value-based goal programing model for product planning using quality function deployment. Engineering Optimization, 37(6), 633-645. https://doi.org/10.1080/03052150500132646

Geng, X., \& Chu, X. (2012). A new importance-performance analysis approach for customer satisfaction evaluation supporting PSS design. Expert Systems with Applications, 39(1), 1492-1502. https://doi.org/10.1016/j.eswa.2011.08.038

Hasenkamp, T. (2010). Engineering design for six sigma - A systematic approach. Quality and Reliability Engineering International, 26(4), 317-324. https://doi.org/10.1002/qre.1090

He, Z., \& Ngee Goh, T. (2015). Enhancing the future impact of six sigma management. Quality Technology \& Quantitative Management, 12(1), 83-92.

https://doi.org/10.1080/16843703.2015.11673368

Hua, Z., Yang, J., Coulibaly, S., \& Zhang, B. (2006). Integration TRIZ with problem-solving tools: A literature review from 1995 to 2006. International Journal of Business Innovation and Research, 1(1-2), 111-128. https://doi.org/10.1504/IJBIR.2006.011091

Kim, T. (2013). Advanced system formwork and construction planning model for tall building construction (Doctoral dissertation). Korea University, Seoul, Korea.

Kim, J. W., Yoo, S. K., \& Kim, J. J. (2010). Efficiency analysis of Euro-form and aluminum-form. Structure \& Construction, 10(1), 41-44.

Kim, T., Lim, H., Lee, U.-K., Cha, M., Cho, H., \& Kang, K.-I. (2012). Advanced formwork method integrated with a layout planning model for tall building construction. Canadian Journal of Civil Engineering, 39(11), 1173-1183. https://doi.org/10.1139/12012-104

Lee, D. (2019). Hybrid system formwork and AI-based construction planning model for high-rise building construction (Doctoral thesis). Korea University, Seoul, Korea.

Lee, J., Lee, D., Cho, H., \& Kang, K. I. (2017). Inhibiting factors and improvement plan of table formwork method in highrise building construction. In Proceedings of the $34^{\text {th }}$ International Symposium on Automation and Robotics in Construction (ISARC 2017) (pp. 571-576). Taipei, Taiwan. https://doi.org/10.22260/ISARC2017/0079

Lee, D., Lim, H., Kim, T., Cho, H., \& Kang, K. I. (2018). Advanced planning model of formwork layout for productivity improvement in high-rise building construction. Automation in Construction, 85, 232-240. https://doi.org/10.1016/j.autcon.2017.09.019

Liang, H. A. N. (2010). Aluminum formwork and its application in high-rise construction of Shenton way project in Singapore. Journal of Qingdao Technological University, 31(6).

Lim, H. S., Kim. T. H., Cho, H. H., \& Kang, K. I. (2012). Design process for formwork system in tall building construction using quality function deployment and TRIZ. Journal of the Architectural Institute of Korea, 28(9), 173-182. 
Lim, H., Kim, T., Cho, H., \& Kang, K.-I. (2017). Simulationbased planning model for table formwork operation in tall building construction. Journal of Asian Architecture and Building Engineering, 16(1), 115-122. https://doi.org/10.3130/jaabe.16.115

Liverani, A., Caligiana, G., Frizziero, L., Francia, D., Donnici, G., \& Dhaimini, K. (2019). Design for Six Sigma (DFSS) for additive manufacturing applied to an innovative multifunctional fan. International Journal of Interactive Design and Manufacturing, 13(1), 309-330.

https://doi.org/10.1007/s12008-019-00548-9

Mayda, M., \& Borklu, H. R. (2014). Development of an innovative conceptual design process by using Pahl and Beitz's systematic design, TRIZ and QFD. Journal of Advanced Mechanical Design, Systems, and Manufacturing, 8(3), 13-00079. https://doi.org/10.1299/jamdsm.2014jamdsm0031

MIK Materials. (2020). www.mikcs.com. Accessed February 24, 2020.

Prasad, B. (1998). Review of QFD and related deployment techniques. Journal of Manufacturing Systems, 17(3), 221-234. https://doi.org/10.1016/S0278-6125(98)80063-0

Sheu, D. D., \& Hou, C. T. (2013). TRIZ-based trimming for process-machine improvements: Slit-valve innovative redesign. Computers \& Industrial Engineering, 66(3), 555-556. https://doi.org/10.1016/j.cie.2013.02.006

Temponi, C., Yen, J., \& Amos Tiao, W. (1999). House of quality: A fuzzy logic-based requirements analysis. European Journal of Operational Research, 117(2), 340-354.

https://doi.org/10.1016/S0377-2217(98)00275-6
Tursch, P., Goldmann, C., \& Woll, R. (2015). Integration of TRIZ into quality function deployment. Management and Production Engineering Review, 6(2), 56-62. https://doi.org/10.1515/mper-2015-0017

Vivek. (2016). Advantages and disadvantages of Mivan shuttering. https://civilareas.wordpress.com/2016/10/19/mivan-shuttering-advantages-and-disadvantages/

Vinodh, S., Kamala, V., \& Jayakrishna, K. (2014). Integration of ECQFD, TRIZ, and AHP for innovative and sustainable product development. Applied Mathematical Modelling, 38(11-12), 2758-2770. https://doi.org/10.1016/j.apm.2013.10.057

Wang, F. K., Yeh, C. T., \& Chu, T. P. (2016). Using the design for six sigma approach with TRIZ for new product development. Computers \& Industrial Engineering, 98, 522-530. https://doi.org/10.1016/j.cie.2016.06.014

Wang, Y. H., Lee, C. H., \& Trappey, A. J. C. (2017). Service design blueprint approach incorporating TRIZ and service QFD for a meal ordering system: A case study. Computers \& Industrial Engineering, 107, 388-400. https://doi.org/10.1016/j.cie.2017.01.013

Yamashina, H., Ito, T., \& Kawada, H. (2002). Innovative product development process by integrating QFD and TRIZ. International Journal of Production Research, 40(5), 1031-1050. https://doi.org/10.1080/00207540110098490

Yeh, C. H., Huang, J. C. Y., \& Yu, C. K. (2011). Integration of four-phase QFD and TRIZ in product R\&D: A notebook case study. Research in Engineering Design, 22(3), 125-141. https://doi.org/10.1007/s00163-010-0099-9 